Werthemann ${ }^{2}$ described a baby with exomphalos and absence of the right leg, hemipelvis, and a single testis. Surveys of infants born to over 3000 women given Debendox in pregnancy ${ }^{4}$ showed no increase in the incidence of abnormalities. We do not therefore necessarily associate the abnormalities seen in the three fetuses described here with the effects of this drug combination. Our patients, however, took Debendox unusually early in pregnancy (five and a half to six weeks after the last menstrual period). As pregnancy is being detected earlier due to the increased use of urine pregnancy tests, fetuses may be exposed more often to drugs during the period of intense organogenesis with consequent increased risk of damage, even from apparently safe drugs like Debendox. We hope our report will alert others to this possibility.

${ }^{1}$ Committee on Safety of Medicines, Register of Adverse Reactions, 1976, pp 320, 469, 618

2 Werthemann, A, in Handbuch der Speziellen Pathologischen Anatomie und Histologie, ed O Lubarsch and F Henke. Berlin, Springer-Verlag, 1952. ${ }^{3}$ Smithells, R W, personal communication.

4 Shapiro, S, et al, American fournal of Obstetrics and Gynecology, 1977, 128, 480 .

(Accepted 30 December 1977)

Department of Medical Genetics, St Mary's Hospital, Manchester M13 0JH

DIAN DONNAI, MRCP, DCH, senior registrar

$R$ HARRIS, MD, FRCP, reader in medical genetics and consultant physician

\section{Bilateral central fracture-dislocation of hips after myelography with meglumine iocarmate (Dimer $\mathbf{X}$ )}

Investigation of suspected lumbar disc protrusions with a contrast medium that mixes with the cerebrospinal fluid outlines the nerve root sheaths (radiculography) and enables a higher proportion of lateral protrusions to be detected than when a non-miscible medium is used. We describe a case of central fracture-dislocation of the hips that occurred after the water-soluble contrast medium meglumine iocarmate (Dimer $\mathrm{X}$ ) was used.

\section{Case report}

A 27-year-old telephonist of previously good health enjoyed a normal pregnancy. Labour was induced at term by surgical rupture of the membranes and delivery effected under epidural anaesthësia using Kielland's rotation forceps. The baby, a boy weighing $3800 \mathrm{~g}$, was normal. After delivery she complained of pain in the lumbar region and left calf. Straight-leg-raising on the left was restricted to $45^{\circ}$. There was no neurological abnormality, and radiographs of the lumbar spine were normal. She was treated with epidural injection, three weeks of bed rest, and a lumbar corset. Her symptoms persisted, and after three months myelography was performed. With the patient lying on her side and the head end of the table raised $15^{\circ}, 7 \mathrm{ml} \mathrm{of}$ meglumine iocarmate mixed with $3 \mathrm{ml}$ of cerebrospinal fluid was introduced into the lumbar canal under television control. Left-sided protrusion of the L4-5 disc was seen (fig 1). After the procedure she was kept sitting up in bed for 12 hours. Her back pain became worse and she developed cramp-like pain in the legs and paraesthesiae, occurring in waves of 10-20 seconds, in the groins and buttocks. Intramuscular diazepam and pentazocine were administered. Twelve hours after myelography she cried out with sudden agonising lower abdominal and groin pain. She was pale, blood pressure was $80 / 50 \mathrm{~mm} \mathrm{Hg}$, there was lower abdominal guarding, and she held her legs rigidly. Right footdrop was noted. Radiography (fig 2) showed bilatera central fracture-dislocation of the hips. She was transfused with 4 units of blood. Under general anaesthesia the hips were manipulated and skeletal traction was applied.

The occurrence of these fractures together with initially low serum calcium $(2.2 \mathrm{mmol} / 1 ; 8.8 \mathrm{mg} / 100 \mathrm{ml})$ and phosphorus $(0.58 \mathrm{mmol} / 1 ; 1.8 \mathrm{mg} / 100 \mathrm{ml})$ concentrations suggested metabolic bone disease. Results of detailed investigations one month later were as follows: serum calcium 2.35-2.70 $\mathrm{mmol} / 1$ (9.4-10.8 $\mathrm{mg} / 100 \mathrm{ml})$, phosphorus $1 \cdot 10-1.42 \mathrm{mmol} / 1$ (3.4-4.4 mg/100 $\mathrm{ml})$, alkaline phosphatase $9 \mathrm{KA}$ units $/ \mathrm{dl}$, and urea $5.2 \mathrm{mmol} / 1 \mathrm{l}(31.3 \mathrm{mg} / 100$ $\mathrm{ml}$ ); no Looser's zones or subperiosteal erosions on skeletal survey; 24-hour urinary calcium and phosphorus $(5.2 \mathrm{mmol}$ and $20.62 \mathrm{mmol}(208 \mathrm{mg}$ and $0.6 \mathrm{~g}$ ) respectively) normal; urine and plasma amino-acid chromatograms normal; iliac bone biopsy normal; and plasma 25-hydroxy vitamin $D$ (20 nmol/1 (8 $\mathrm{ng} / \mathrm{ml})$ ) normal. . Serum parathyroid hormone was not measured owing to positivity to hepatitis $\mathrm{B}$ antigen.

On mobilisation at 12 weeks she developed recurrence of the left sciatic $\underline{\square}$ pain. The disc protrusion was excised and the nucleus pulposus evacuated

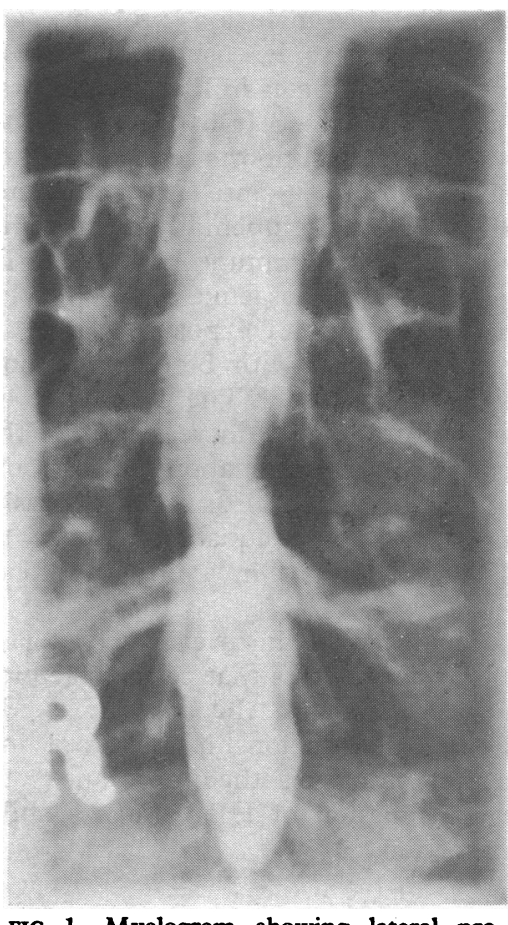

FIG 1-Myelogram showing lateral protrusion of L4-5 disc.

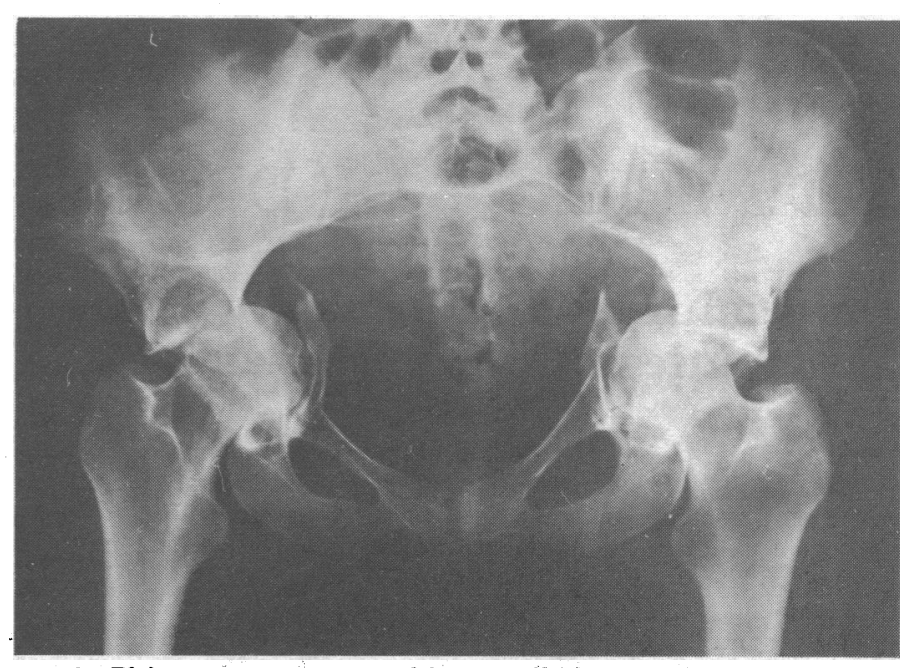

FIG 2-Plain $x$-ray appearances of fracture-dislocation of hips.

using a fenestration approach. Nine months after the fractures she was free of sciatic pain but both hips were painful and very stiff. The right footdrop had resolved.

\section{Comment}

Because of the side effects of water-soluble contrast media used for myelography some radiologists prefer iophendylate (Myodil). Clonic $\stackrel{\partial}{\supset}$ spasms, fractures, and death have followed the use of meglumine iothalamate (Conray). ${ }^{1}$ Severe bilateral pelvic fractures have also been described. ${ }^{2}$ Meglumine iocarmate, a dimer of meglumine iothalamate, was reported by Danziger and Bloch ${ }^{3}$ to have few serious side effects. 
In a series of 451 lumbar myelograms, however, Selby et al ${ }^{4}$ reported clonic muscle spasms of the legs in four patients. A fracture of the femoral neck caused by muscle spasm after meglumine iocarmate lumbar myelography has also been reported. ${ }^{2}$ The occurrence of any such fracture raises the possibility of metabolic bone disease. In our patient the suspicion proved unfounded, and we can attribute these disastrous fractures only to severe clonic spasm after the use of meglumine iocarmate.

The side effects of meglumine iocarmate myelography are probably more common when the contrast medium is allowed to remain in contact with the cord. Thus after the investigation the patient must be kept in the sitting position for at least six hours, by which time most of the medium should have been absorbed. Nursing staff should be cautioned not to lay the patient flat should hypotension, a recognised side effect of meglumine iocarmate myelography, ${ }^{3}$ occur. If muscle spasms develop diazepam must be given immediately and in sufficient dosage.

We regard the fractures described here, albeit rare, as such a serious complication that we have now abandoned the use of meglumine iocarmate for lumbar myelography and use metrizamide
(Amipaque). ${ }^{5}$ We have been unable to trace any reports of fracture after myelography with metrizamide.

We thank Miss P M Turnbull and the department of medical illustration, Charing Cross Hospital Medical School, for preparing the figures, and Mrs $\mathrm{J} \mathrm{K}$ Lyall for typing the manuscript.

1 Christiansen, A H, Ugeskrift for Laeger, 1974, 136, 1579.

${ }^{2}$ Hugander, A, et al, Zeitschrift für Rechtsmedizin, 1974, 75, 219.

3 Danziger, J, and Bloch, S, Clinical Radiology, 1973, 24, 231.

4 Selby, D K, et al, Orthopedic Clinics of North America, 1977, 8, 79.

5 Ahlgren, P, Neuroradiology, 1975, 9, 197.

(Accepted 30 December 1977)

Charing Cross Hospital Medical School, London W6 8RF

J B EASTWOOD, MD, MRCP, lecturer in medicine

Kingston Hospital, Kingston-upon-Thames, Surrey

B PARKER, MB, FRCS, consultant orthopaedic surgeon

B R REID, MB, FRCR, consultant radiologist

\section{SHORT REPORTS}

\section{Fatal chlormethiazole poisoning in chronic alcoholics}

(This paper is a revised version of a short report previously published ( 3 September 1977, $p$ 614) which contained certain errors (see correspondence ( $p$ 716) and leading article ( $p$ 668)). It replaces and augments the previous version.-ED, BMF.)

Chlormethiazole edisylate (Heminevrin) is a sedative, hypnotic, and anticonvulsant drug. ${ }^{1}$ It is widely used in the treatment of acute withdrawal symptoms in alcoholics. However, it is seldom recommended in alcoholic withdrawal to administer the drug for more than six to seven days because of the danger of psychological or, rarely, physical dependence. ${ }^{2}$ It is stated to be of low toxicity, but its effects are additive with alcohol and barbiturates. I describe five fatal cases of selfpoisoning in chronic alcoholics, all of whom were being treated with chlormethiazole edisylate in tablet form.

\section{Case reports}

Case 1-The patient was a single man aged 45 years who was a known chronic alcoholic. He was depressed and had made two previous suicide attempts. He had been implicated in a minor traffic accident and charged with driving under the influence of drugs. Analysis of a blood sample at the time showed it to contain $2.6 \mathrm{mg} / 100 \mathrm{ml}$ of chlormethiazole base. No alcohol was detected. Four days later he was found dead in his flat. Post-mortem examination showed adherent pinkish-white powder in the upper third of the oesophagus and 10 whole white tablets in the stomach. The lungs were oedematous. No appreciable natural disease was found.

Case 2-The patient, a 60-year-old single man, was a known chronic alcoholic who had had psychiatric treatment for depression. He was found dead in a wood with a bottle nearby that contained chlormethiazole tablets. Post-mortem examination showed adherent white powder in the lower third of the oesophagus and 20 whole white tablets with a sickly sweet smell in the stomach. Recent thrombus had occluded the right coronary artery and a large area of fibrosis was present in the interventricular septum.

Case 3-The patient was a man of 47 years. He had been an alcoholic for 20 years with fits of depression and attempts at suicide. He was found dead at home with a bottle of chlormethiazole tablets nearby. Necropsy showed 65 whole white tablets and much white granular material with a sickly sweet smell in the stomach. There was no appreciable natural disease.

Case 4-This patient, a known alcoholic, was a single man aged 52 years. Shortly before his death he had become depressed and had been admitted to a psychiatric unit. The day after his discharge he was found dead on a river embankment. White sludge and 18 whole white tablets with a sickly sweet smell were found in the stomach at necropsy. There was adherent white powder in the lower oesophagus and severe coronary atherosclerosis.

Case 5-The patient, a woman of 48 years, was a known alcoholic and depressive. At the time of her death she was on bail for shoplifting. She was found dead in her hostel room with an empty bottle that had contained chlormethiazole tablets nearby. Post-mortem examination showed two whole white tablets, white sludge, and mucoid brown fluid in the stomach. No appreciable natural disease was found.

A toxicological examination was performed in each of the five cases (see table).

Chlormethiazole (measured as base) and alcohol concentrations in blood and urine $(\mathrm{mg} / 100 \mathrm{ml})$ and liver $(\mathrm{mg} / 100 \mathrm{~g})$ from five alcoholic patients who died after self-poisoning with chlormethiazole edisylate tablets

\begin{tabular}{|c|c|c|c|c|c|c|}
\hline \multirow{2}{*}{$\begin{array}{l}\text { Patient } \\
\text { No }\end{array}$} & \multicolumn{2}{|c|}{ Blood } & \multicolumn{2}{|c|}{ Urine } & \multicolumn{2}{|c|}{ Liver } \\
\hline & $\begin{array}{c}\text { Chlor- } \\
\text { methiazole }\end{array}$ & Alcohol & $\begin{array}{c}\text { Chlor- } \\
\text { methiazole }\end{array}$ & Alcohol & $\begin{array}{c}\text { Chlor- } \\
\text { methiazole }\end{array}$ & Alcohol \\
\hline 1 & $4 \cdot 0$ & Nil & 6.5 & Nil & $6 \cdot 2$ & $\mathrm{NE}$ \\
\hline 2 & 6.0 & Nil & $8 \cdot 0$ & Nil & $19 \cdot 0$ & $\mathrm{NE}$ \\
\hline 3 & 1.8 & 224 & $1 \cdot 0$ & 225 & $6 \cdot 2$ & $\mathrm{NE}$ \\
\hline 4 & 1.0 & 88 & $2 \cdot 8$ & 133 & $10 \cdot 0$ & $\mathrm{NE}$ \\
\hline 5 & $2 \cdot 0$ & Nil & $2 \cdot 0$ & 100 & 6.0 & $\mathrm{NE}$ \\
\hline
\end{tabular}

$\mathrm{NE}=$ Not estimated

\section{Comment}

In a series of nine cases of death from chlormethiazole poisoning alone Jakobsson and Möller reported the lowest recorded fatal plasma concentration of the drug- $2.5 \mathrm{mg} / 100 \mathrm{ml}$ (range $2.5-8.0 \mathrm{mg} / 100 \mathrm{ml}$ ). ${ }^{3}$ Nevertheless, the patient described in case 1 was driving a car, albeit unsuccessfully, with a plasma concentration of $2.6 \mathrm{mg} / 100 \mathrm{ml}$. Clearly there must be individual variation in reaction to the drug or the development of tolerance. Fatal concentrations of the drug when taken with alcohol are very much lower. Similar concentrations to those in cases 3 and 4 were found in a series in which the mean plasma concentration of chlormethiazole base was $2 \cdot 1 \mathrm{mg} / 100 \mathrm{ml}$ (range $0 \cdot 5-4 \cdot 7$ $\mathrm{mg} / 100 \mathrm{ml}) .^{3}$ The presence of alcohol in the urine but its absence in the blood in case 5 suggests that the alcohol was consumed several hours before death.

From the amount of unabsorbed drug in the stomach in each case it is clear that the therapeutic dose had been exceeded. The tablets are dispensed in bottles of 100 and this was the usual quantity prescribed for patients under the care of general practitioners at the time these deaths occurred. ${ }^{4}$ Prescribing smaller quantities does not, however, prevent hoarding. Chlormethiazole is a useful drug for the treatment of acute withdrawal symptoms in alcoholics under strict supervision in hospital. Nevertheless, a potentially dangerous situation arises when the drug is prescribed for an alcoholic when under the care of a general practitioner or as an outpatient. In these circum- 